Pacific Journal of Mathematics

UNITARY EQUIVALENCE OF INVARIANT SUBSPACES IN THE

(l) 


\title{
UNITARY EQUIVALENCE OF INVARIANT SUBSPACES IN THE POLYDISK
}

\author{
KEIJI IZUCHI
}

\begin{abstract}
Invariant subspaces $M$ and $N$ of $H^{2}\left(T^{n}\right)$ are called unitarily equivalent if $M=\psi N$ for a unimodular function $\psi$ on $T^{n}$. In this note, it is given a complete characterization of pairs of invariant subspaces $M$ and $N$ of $H^{2}\left(T^{n}\right)$ such that $M=\phi N$ for an inner function $\phi$. This is a generalization of Agrawal, Clark and Douglas' results. As an application, if $M$ is an invariant subspace of $H^{2}\left(T^{n}\right)$ and if $M$ is unitarily equivalent to $S(f)$, an invariant subspace generated by an outer function $f$, then $M=\phi S(f)$ for some inner function $\phi$.
\end{abstract}

It is well known that Beurling [4] showed that every invariant subspace $M$ of $H^{2}(T)$ can be written by $M=\psi H^{2}(T)$ for some inner function $\psi$. Although it is easy to see that a Beurling-type characterization is not possible for invariant subspaces of $H^{2}\left(T^{n}\right), n \geq 2$, it is very difficult to determine all invariant subspaces of $H^{2}\left(T^{n}\right)$ for $n \geq 2$. In [3], Ahern and Clark studied an invariant subspace which has finite codimension in $H^{2}\left(T^{n}\right)$. These invariant subspaces are not Beurling-type. Recently Agrawal, Clark and Douglas [2] studied pairs of invariant subspaces of $H^{2}\left(T^{n}\right)$ which are unitarily equivalent. Here two invariant subspaces $M_{1}$ and $M_{2}$ are called unitarily equivalent if there is a unimodular function $\psi$ on $T^{n}$ with $M_{2}=\psi M_{1}$. In [1, Corollary 3], they showed that distinct invariant subspaces having finite codimensions in $H^{2}\left(T^{n}\right)$ are not unitarily equivalent. In [9], Rudin gives two examples of unitarily equivalent invariant subspaces of $H^{2}\left(T^{2}\right)$ answering problems posed in [2]. In [6], Nakazi gives a characterization of invariant subspaces $M$ of $L^{2}\left(T^{2}\right)$ with $M=F H^{2}\left(T^{2}\right)$ for some unimodular function $F$. From the view point of the Beurling theorem, it is interesting to characterize pairs of unitarily equivalent subspaces $M_{1}$ and $M_{2}$ of $H^{2}\left(T^{n}\right)$ such that $M_{2}=\psi M_{1}$ for some inner function $\psi$. In [2], they give some sufficient conditions of these pairs. One of these conditions is $M_{2} \subset M_{1}$.

In §2, we shall show a theorem which contains Schneider's lemma as a corollary (Corollary 1). Also our theorem gives us a complete characterization of pairs of invariant subspaces $M_{1}$ and $M_{2}$ of $H^{2}\left(T^{n}\right)$ such that $M_{2}=\psi M_{1}$ for some inner function $\psi$ (Corollary 2). Of course this 
theorem covers Propositions 1, 2, 3, and 4 in [2]. In \$3, we shall study invariant subspaces which are unitarily equivalent to the one generated by an outer function.

1. Notations and Theorems. For a positive integer $n$, let $T^{n}$ denote the cartesian product of $n$ unit circles. The usual Lebesgue spaces, with respect to the normalized Haar measure $m_{n}$ on $T^{n}$, are denoted by $L^{p}\left(T^{n}\right), 1 \leq p \leq \infty$. Let $H^{p}\left(T^{n}\right)$ be the space of all $f$ in $L^{p}\left(T^{n}\right)$ whose Fourier transforms

$$
\hat{f}(\alpha)=\int_{T^{n}} f(z) \bar{z}_{1}^{\alpha_{1}} \bar{z}_{2}^{\alpha_{2}} \cdots \bar{z}_{n}^{\alpha_{n}} d m_{n}(z)
$$

vanish outside $\left(Z_{+}\right)^{n}$, the $n$-fold product of nonnegative integers. A function $\psi$ in $L^{\infty}\left(T^{n}\right)$ and $H^{\infty}\left(T^{n}\right)$ is called unimodular and inner if $|\psi|=1$ a.e. $d m_{n}$, respectively. A closed subspace $M$ of $L^{2}\left(T^{n}\right)$ is called invariant if $z_{i} M \subset M$ for every $i=1,2, \ldots, n$. We note that if $M$ is an invariant subspace then $H^{\infty}\left(T^{n}\right) M \subset M$. A function $f$ in $H^{2}\left(T^{n}\right)$ is called outer if

$$
\log |f(0)|=\int_{T^{n}}|f(z)| d m_{n}(z) .
$$

We denote by $S(f)$ the invariant subspace generated by a function $f$ in $L^{2}\left(T^{n}\right)$. [8] is a convenient reference for the function theory in the polydisk.

To state our theorem, we use the following notations. Let $H_{k}$ and $\mathscr{H}_{k}$ denote the closure in $L^{2}\left(T^{n}\right)$ of the algebra generated by

$$
\begin{aligned}
& \left\{1, z_{i} ; i=1,2, \ldots, n\right\} \cup\left\{\bar{z}_{k}\right\} \text { and } \\
& \left\{1, z_{i}, \bar{z}_{i}: i=1,2, \ldots, n\right\} \backslash\left\{\bar{z}_{k}\right\},
\end{aligned}
$$

respectively. Let $L_{k}^{p}$ denote the closure in $L^{p}\left(T^{n}\right)$, weak*-closure if $p=\infty$, of the algebra generated by

$$
\left\{1, z_{l}, \bar{z}_{i}: i=1,2, \ldots, n\right\} \backslash\left\{z_{k}, \bar{z}_{k}\right\} .
$$

Then $H_{k}$ and $\mathscr{H}_{k}$ are invariant subspaces, $\bigcap_{k=1}^{n} \mathscr{H}_{k}=H^{2}\left(T^{n}\right)$, and $\mathscr{H}_{k}$ coincides with the closed linear span of $\left\{z_{k}^{m} L_{k}^{2} ; m=0,1,2, \ldots\right\}$.

For an invariant subspace $M$ (generally not closed), let $(M)_{k}$ denote the closure of $L_{k}^{\infty} M$ in $L^{2}\left(T^{n}\right)$. Then $(M)_{k}$ is an invariant subspace and $L_{k}^{\infty}(M)_{k}=(M)_{k}$. We note $\left(H^{2}\left(T^{n}\right)\right)_{k}=\mathscr{H}_{k}$. A closed subspace $N$ of $L^{2}\left(T^{n}\right)$ is called reducing if $z_{l} N=N$ for every $i=1,2, \ldots, n$. If $N$ is reducing, then $L^{\infty}\left(T^{n}\right) N=N$, hence $N=\chi_{U} L^{2}\left(T^{n}\right)$, where $\chi_{U}$ is a characteristic function for a Borel subset $U$ of $T^{n}$. We note that $\mathscr{H}_{k}$ does not contain any reducing subspaces. 
Our main results are

THEOREM 1. Let $M_{1}$ be an invariant subspace of $H^{2}\left(T^{n}\right)$ and $\phi \in$ $L^{\infty}\left(T^{n}\right)$. Let $M_{2}$ denote the closure of $\phi M_{1}$ in $L^{2}\left(T^{n}\right)$. Then $\phi \in H^{\infty}\left(T^{n}\right)$ if and only if $\left(M_{2}\right)_{k} \subset\left(M_{1}\right)_{k}$ for every $k=1,2, \ldots, n$.

Corollary 7. Let $f \in H^{2}\left(T^{n}\right)$ be an outer function, and $M$ be an invariant subspace of $H^{2}\left(T^{n}\right)$ which is unitarily equivalent to $S(f)$. Then $M=\psi S(f)$ for some inner function $\psi$.

2. Proof of Theorem 1 and its applications. The following lemma is a corollary of the Merrill and Lal theorem [5] (see Remark after Lemma 1). In this case, we can prove it directly. For the sake of completeness, we give its proof.

Lemma 1. Let $M$ be an invariant subspace of $H^{2}\left(T^{n}\right)$. Then for each $k=1,2, \ldots, n,(M)_{k}=F_{k} \mathscr{H}_{k}$ for a unimodular function $F_{k}$ in $\mathscr{H}_{k}$.

Proof. Let fix $k$. Since $M \subset H^{2}\left(T^{n}\right), \quad(M)_{k} \subset \mathscr{H}_{k}$. Hence $\bigcap_{l=1}^{\infty} z_{k}^{i}(M)_{k}=\{0\}$. Put

$$
N=(M)_{k} \ominus z_{k}(M)_{k} .
$$

Then $N \neq\{0\}$. Since $L_{k}^{\infty}(M)_{k}=(M)_{k}, L_{k}^{\infty} N=N$. Thus we have

$$
(M)_{k}=N \oplus z_{k} N \oplus z_{k}^{2} N \oplus \cdots .
$$

Let $g \in N$. Since $g \perp g z_{k}^{i}$ for $i=1,2, \ldots$, we get

$$
\int_{T^{n}}|g|^{2} z_{k}^{i} d m_{n}=0
$$

for every nonzero integer $i$. This implies $|g| \in L_{k}^{2}$. Since $|f|>0$ a.e. $d m_{n}$ for $f \in H^{2}\left(T^{n}\right)$, by (1) there exists $g_{0}$ in $N$ such that $\left|g_{0}\right|>0$ a.e. $d m_{n}$. Put $g_{0}=F\left|g_{0}\right|$, where $F$ is unimodular. Since $L_{k}^{\infty} N=N, N \supset L_{k}^{\infty} g_{0}=$ $F L_{k}^{\infty}\left|g_{0}\right|$. Since $L_{k}^{\infty}\left|g_{0}\right|$ is dense in $L_{k}^{2}$, we have $F L_{k}^{2} \subset N$.

To show $F L_{k}^{2}=N$, let $g \in N$. Since $F \in N$,

$$
F z_{k}^{i} \perp g z_{k}^{j}
$$

for every $i, j \geq 0$ with $i \neq j$. Hence

$$
\int_{T^{n}} \bar{F} g z_{k}^{p} d m_{n}=0
$$


for every nonzero integer $p$. Thus $\bar{F} g \in L_{k}^{2}$, so that $g \in F L_{k}^{2}$. Consequently $F L_{k}^{2}=N$. By (1),

$$
(M)_{k}=F L_{k}^{2} \oplus F z_{k} L_{k}^{2} \oplus F z_{k}^{2} L_{k}^{2} \oplus \cdots=F \mathscr{H}_{k} .
$$

Since $F \in(M)_{k} \subset \mathscr{H}_{k}$, this completes the proof.

REMARK. In [5], they showed the following (in more general form); if $M$ is an invariant subspace of $L^{2}\left(T^{n}\right)$ with $z_{l} M=M$ for $i=1,2, \ldots, n$ with $i \neq k$, then $M=\chi_{U} F \mathscr{H}_{k} \oplus \chi_{V} L^{2}\left(T^{n}\right)$, where $F$ is unimodular. In this case, it is easy to see that $M=F \mathscr{H}_{k}$ if and only if $M$ has no reducing subspaces and there is a function $f$ in $M$ with $|f|>0$ a.e. $d m_{n}$. This fact is essentially pointed out, for the case $n=2$, by Nakazi (see [6, Theorem 6]). Using this fact, we can also prove Lemma 1.

Proof of Theorem 1. Let $M_{1}$ be an invariant subspace of $H^{2}\left(T^{n}\right)$, $\phi \in L^{\infty}\left(T^{n}\right)$ and $M_{2}$ be the closure of $\phi M_{1}$ in $L^{2}\left(T^{n}\right)$. By Lemma 1, $\left(M_{1}\right)_{k}=F_{k} \mathscr{H}_{k}$ for some unimodular function $F_{k}$ for $k=1,2, \ldots, n$.

First suppose that $\left(M_{1}\right)_{k} \supset\left(M_{2}\right)_{k}$ for $k=1,2, \ldots, n$. Then

$$
F_{k} \mathscr{H}_{k}=\left(M_{1}\right)_{k} \supset\left(M_{2}\right)_{k} \supset \phi\left(M_{1}\right)_{k}=\phi F_{k} \mathscr{H}_{k} \text {. }
$$

Hence $\phi \mathscr{H}_{k} \subset \mathscr{H}_{k}$, so that $\phi \in \bigcap_{k=1}^{n} \mathscr{H}_{k}=H^{2}\left(T^{n}\right)$. Thus $\phi \in H^{\infty}\left(T^{n}\right)$.

Next suppose $\phi \in H^{\infty}\left(T^{n}\right)$. We note that $\left(M_{2}\right)_{k}$ coincides with the closure of $\phi\left(M_{1}\right)_{k}$ in $L^{2}\left(T^{n}\right)$. Since $\phi \mathscr{H}_{k} \subset \mathscr{H}_{k}$, we have

$$
\phi\left(M_{1}\right)_{k}=\phi F_{k} \mathscr{H}_{k} \subset F \mathscr{H}_{k}=\left(M_{1}\right)_{k} .
$$

Thus $\left(M_{2}\right)_{k} \subset\left(M_{1}\right)_{k}$. This completes the proof.

The following corollary is proved in [2, Proposition 3] using an idea of Schneider [10]. We can prove this as an application of our theorem.

Corollary 1. Let $\phi \in L^{\infty}\left(T^{n}\right)$ and $f \in H^{2}\left(T^{n}\right)$ such that $f \neq 0$ and $\phi^{m} f \in H^{2}\left(T^{n}\right)$ for $m=1,2, \ldots$ Then $\phi \in H^{\infty}\left(T^{n}\right)$.

Proof. Let $M_{1}$ denote the invariant subspace of $H^{2}\left(T^{n}\right)$ generated by $\left\{\phi^{m} f ; m=1,2, \ldots\right\}$. Let $M_{2}$ denote the closure of $\phi M_{1}$ in $L^{2}\left(T^{n}\right)$. Then $M_{2} \subset M_{1} \subset H^{2}\left(T^{n}\right)$, so that $\left(M_{2}\right)_{k} \subset\left(M_{1}\right)_{k}$ for $k=1,2, \ldots, n$. By Theorem $1, \phi \in H^{\infty}\left(T^{n}\right)$.

The following is a direct corollary of our theorem. This answers the question posed in the introduction. 
Corollary 2. Let $M_{1}$ and $M_{2}$ be unitarily equivalent invariant subspaces of $H^{2}\left(T^{n}\right)$. Put $M_{2}=\psi M_{1}$, where $\psi$ is unimodular. Then $\psi$ is inner if and only if $\left(M_{1}\right)_{k} \supset\left(M_{2}\right)_{k}$ for every $k=1,2, \ldots, n$.

Corollary 3. Let $M_{1}$ and $M_{2}$ be invariant subspaces of $H^{2}\left(T^{n}\right)$ such that $\left(M_{1}\right)_{k}=\left(M_{2}\right)_{k}$ for $k=1,2, \ldots, n$. Then $M_{1}$ is unitarily equivalent to $M_{2}$ if and only if $M_{1}=M_{2}$.

Proof. Suppose that $M_{2}=\psi M_{1}$ and $\psi$ is unimodular. By Corollary 2, $\psi$ and $\bar{\psi}$ are inner. Hence $\psi$ is constant, so that $M_{1}=M_{2}$.

Corollary 4. Let $M_{1}$ be an invariant subspace of $H^{2}\left(T^{n}\right)$ such that $\left(M_{1}\right)_{k}=\mathscr{H}_{k}$ for $k=1,2, \ldots, n$. If $M_{2}$ is an invariant subspace of $H^{2}\left(T^{n}\right)$ with $M_{2}=\psi M_{1}$, where $\psi$ is unimodular, then $\psi$ is inner.

$$
\begin{aligned}
& \text { Proof. Since } M_{2} \subset H^{2}\left(T^{n}\right), \\
& \qquad\left(M_{2}\right)_{k} \subset\left(H^{2}\left(T^{n}\right)\right)_{k}=\mathscr{H}_{k}=\left(M_{1}\right)_{k} .
\end{aligned}
$$

By Corollary 2, $\psi$ is inner.

An invariant subspace $M$ of $H^{2}\left(T^{n}\right)$ has full range if the closed linear span of $\left\{\bar{z}_{k}^{m} M ; m=1,2, \ldots\right\}$ coincides with $H_{k}$ for $k=1,2, \ldots, n$ (see [2, p. 5]).

By the following lemma, we can consider that Corollary 4 is a generalization of both Propositions 1 and 2 in [2].

LEMma 2. Let $M$ be one of the following invariant subspaces of $H^{2}\left(T^{n}\right)$.

(1) $M$ has full range.

(2) $M$ contains a nonzero function independent of $z_{k}$ for each $k=$ $1,2, \ldots, n$.

Then $(M)_{k}=\mathscr{H}_{k}$ for $k=1,2, \ldots, n$.

Proof. (1) Suppose that $M$ has full range. Then by the definitions, $H_{l} \subset(M)_{k}$ for $i \neq k$. Since $\mathscr{H}_{k}$ coincides with the linear span of $\left\{H_{l}\right.$; $i=1,2, \ldots, n$ and $i \neq k\}$, we get $\mathscr{H}_{k} \subset(M)_{k}$, so that $\mathscr{H}_{k}=(M)_{k}$.

(2) Suppose that $f_{k} \in M$ is a nonzero function independent of $z_{k}$. Then

$$
\begin{aligned}
(M)_{k} & =\text { the closure of } L_{k}^{\infty} M \text { in } L^{2}\left(T^{n}\right) \\
& \supset \text { the closure of } L_{k}^{\infty} f_{k} \text { in } L^{2}\left(T^{n}\right)=L_{k}^{2},
\end{aligned}
$$

the last equality follows from $\left|f_{k}\right|>0$ a.e. $d m$. Since $z_{k}(M)_{k} \subset(M)_{k}$, we get $\mathscr{H}_{k} \subset(M)_{k}$, so that $\mathscr{H}_{k}=(M)_{k}$. 
The following example shows that Corollary 4 is not covered by the work of Agrawal, Clark and Douglas [2].

EXAMPLE. For cases $n \geq 3$, there is an invariant subspace $M$ of $H^{2}\left(T^{n}\right)$ such that

(a) $M$ does not contain a function independent of $z_{k}$,

(b) $M$ does not have full range, and

(c) $(M)_{k}=\mathscr{H}_{k}$ for $k=1,2, \ldots, n$.

We shall show the existence of $M$ as above for $n=3$. Let $\left\{\psi_{l}\right\}_{l=0}^{\infty}$ be a sequence of nonconstant inner functions in $H^{\infty}(T)$ satisfying the following conditions.

(i) $\psi_{1} H^{2}(T) \subsetneq \psi_{1+1} H^{2}(T)$ for every $i$, and

(ii) $\bigcup_{l=0}^{\infty} \psi_{l} H^{2}(T)$ is dense in $H^{2}(T)$.

Let $M$ denote the invariant subspace of $H^{2}\left(T^{3}\right)$ generated by

$$
\bigcup_{i=0}^{\infty} \bigcup_{J=0}^{\infty} z_{1}^{i} z_{2}^{j} \psi_{j}\left(z_{3}\right) H^{2}\left(T^{3}\right) \text {. }
$$

Then every nonzero function in $M$ is not independent of $z_{3}$. Hence $M$ satisfies (a). By (i), $\psi_{0}\left(z_{3}\right) H^{2}\left(T^{3}\right) \subsetneq H^{2}\left(T^{3}\right)$. Hence by the definition of $M$, the linear span of $\left\{\bar{z}_{1}^{m} M ; m=1,2, \ldots\right\}$ does not contain $H^{2}\left(T^{3}\right)$, because it does not contain nonconstant functions. Thus $M$ satisfies (b). By (ii), $(M)_{3}=\mathscr{H}_{3}$. Since the linear span of $\left\{z_{3}^{k} \psi_{j}\left(z_{3}\right) ; k\right.$ is an integer $\}$ coincides with $L^{2}(T)$, we have $(M)_{k}=\mathscr{H}_{k}$ for $k=1,2$. Thus $M$ satisfies (c).

Corollary 5 [2, Proposition 4]. Let $M$ and $M_{1}$ be invariant subspaces of $H^{2}\left(T^{n}\right)$ such that $M \supset M_{1}$ and $M_{1}$ has finite codimension in $M$. If $M_{2}$ is an invariant subspace of $M$ with $M_{2}=\psi M_{1}$, where $\psi$ is unimodular, then $\psi$ is inner.

Proof. Since $M \ominus M_{1}$ has finite dimension, it is easy to see $(M)_{k}=$ $\left(M_{1}\right)_{k}$ for $k=1,2, \ldots, n$. Since $M \supset M_{2},\left(M_{2}\right)_{k} \subset(M)_{k}=\left(M_{1}\right)_{k}$. By Corollary $2, \psi$ is inner.

Corollary 6. Let $M_{1}$ and $M_{2}$ be invariant subspaces of $H^{2}\left(T^{n}\right)$. Suppose that both of $M_{1} \ominus M_{2}$ and $M_{2} \ominus M_{1}$ have finite dimensions. Then $M_{1}$ and $M_{2}$ are unitarily equivalent if and only if $M_{1}=M_{2}$.

Proof. Let $M$ denote the invariant subspace generated by $M_{1}$ and $M_{2}$. Then $M_{1}$ and $M_{2}$ have finite codimensions in $M$. Put $M_{2}=\psi M_{1}$ for some unimodular function $\psi$. By Corollary $5, \psi$ is constant, so that $M_{1}=M_{2}$. 
3. Outer functions. Rudin [7] showed the following.

(i) If $S(f)=H^{2}\left(T^{n}\right)$ and $f \in H^{2}\left(T^{n}\right)$, then $f$ is outer.

(ii) There is an outer function $f$ such that $S(f) \neq H^{2}\left(T^{n}\right)$.

If $M$ is an invariant subspace of $H^{2}\left(T^{n}\right)$ such that $M$ is unitarily equivalent to $H^{2}\left(T^{n}\right)$, then $M=\psi H^{2}\left(T^{n}\right)$ for some inner function $\psi$ [2, Corollary 1]. In this section, we shall show that the above assertion is true if $H^{2}\left(T^{n}\right)$ is replaced by $S(f)$ for outer functions $f$.

THEOREM 2. Let $f \in H^{2}\left(T^{n}\right)$ be an outer function. Then $(S(f))_{k}=\mathscr{H}_{k}$ for every $k=1,2, \ldots, n$.

By Corollary 4, we get

Corollary 7. Let $f \in H^{2}\left(T^{n}\right)$ be an outer function and let $M$ be an invariant subspace of $H^{2}\left(T^{n}\right)$. If $M$ is unitarily equivalent to $S(f)$, then $M=\psi S(f)$ for some inner function $\psi$.

Proof of Theorem 2. Let $f \in H^{2}\left(T^{n}\right)$ be an outer function. Without loss of generality, we may assume $k=n$. By Lemma $1,(S(f))_{n}=F_{n} \mathscr{H}_{n}$ for some unimodular function $F_{n}$ in $\mathscr{H}_{n}$. We shall show that $F_{n}$ is independent of $z_{n}$. We can write $f=F_{n} h$, where $h \in \mathscr{H}_{n}$. Write

$$
z=\left(z^{\prime}, z_{n}\right) \in T^{n}, \quad \text { where } z^{\prime} \in T^{n-1} .
$$

Since $f, F_{n}$ and $h$ are contained in $\mathscr{H}_{n}$, there is a Borel subset $E$ of $T^{n-1}$ with $m_{n-1}(E)=1$ such that for every fixed $z^{\prime} \in E$,

$$
f\left(z^{\prime}, z_{n}\right), F_{n}\left(z^{\prime}, z_{n}\right), h\left(z^{\prime}, z_{n}\right) \in H^{2}(T)
$$

and $F_{n}\left(z^{\prime}, z_{n}\right)$ is inner. Since $f\left(z^{\prime}, 0\right) \in H^{2}\left(T^{n-1}\right)$,

$$
\begin{aligned}
\log |f(0)| & =\log \left|\int_{T^{n-1}} f\left(z^{\prime}, 0\right) d m_{n-1}\left(z^{\prime}\right)\right| \\
& \leq \int_{T^{n-1}} \log \left|f\left(z^{\prime}, 0\right)\right| d m_{n-1}\left(z^{\prime}\right) \quad \text { by }[8, \mathrm{p} .47]
\end{aligned}
$$

Hence, by our assumption,

$$
\int_{T^{n-1}}\left\{\log \left|f\left(z^{\prime}, 0\right)\right|-\int_{T} \log \left|f\left(z^{\prime}, z_{n}\right)\right| d m_{1}\left(z_{n}\right)\right\} d m_{n,-1}\left(z^{\prime}\right) \geq 0 .
$$

Since $\log \left|f\left(z^{\prime}, 0\right)\right| \leq \int_{T} \log \left|f\left(z^{\prime}, z_{n}\right)\right| d m_{1}\left(z_{n}\right)$ for $z^{\prime} \in E$,

$$
\log \left|f\left(z^{\prime}, 0\right)\right|=\int_{T} \log \left|f\left(z^{\prime}, z_{n}\right)\right| d m_{1}\left(z_{n}\right) \quad \text { a.e. } z^{\prime} \in E .
$$


Thus $f\left(z^{\prime}, z_{n}\right)$ is outer for a.e. $z^{\prime} \in E$. Since $f=F_{n} h$, for a.e. fixed $z^{\prime} \in E$, we have

$$
f\left(z^{\prime}, z_{n}\right)=F_{n}\left(z^{\prime}, z_{n}\right) h\left(z^{\prime}, z_{n}\right) \text { a.e. } z_{n} \in T \text {. }
$$

By (2), an inner function $F_{n}\left(z^{\prime}, z_{n}\right)$ is constant for a.e. $z^{\prime} \in E$. Then for nonzero integers $i$,

$$
\int_{T^{n}} F_{n}(z) z_{n}^{i} d m_{n}(z)=\int_{T^{n-1}} d m_{n-1}\left(z^{\prime}\right) \int_{T} F_{n}\left(z^{\prime}, z_{n}\right) z_{n}^{l} d m_{1}\left(z_{n}\right)=0 .
$$

This implies that $F_{n}(z)$ is independent of $z_{n}$. Hence $F_{n}$ is invertible in $\mathscr{H}_{n}$, so that we get $(S(f))_{n}=\mathscr{H}_{n}$. This completes the proof.

\section{REFERENCES}

[1] O. P. Agrawal, Invariant subspaces of shift operator for the quarter plane, $\mathrm{PhD}$ Thesis, SUNY Stony Brook, 1983.

[2] O. P. Agrawal, D. N. Clark and R. G. Douglas, Invariant subspaces in the polydisk, Pacific J. Math., 121 (1986), 1-11.

[3] P. R. Ahern and D. N. Clark, Invariant subspaces and analytic continuation in several variables, J. Math. Mech., 19 (1970), 963-969.

[4] A. Beurling, On two problems concerning linear transformations in Hilbert space, Acta Math., 81 (1949), 239-255.

[5] S. Merrill and N. Lal, Characterization of certain invariant subspaces of $H^{p}$ and $L^{p}$ spaces derived from logmodular algebras, Pacific J. Math., 30 (1969), 463-474.

[6] T. Nakazi, Certain invariant subspaces of $H^{2}$ and $L^{2}$ on a bidisc, Preprint.

[7] W. Rudin, Proof of a conjecture of Helson, Bull. Amer. Math. Soc., 74 (1968), 727-729.

[8] _ _ Function Theory in Polydiscs, Benjamin, New York, 1969.

[9] Invariant subspaces of $H^{2}$ on a torus, J. Functional Anal., 61 (1985), 378-384.

[10] R. B. Schneider, Isometries of $H^{p}\left(U^{n}\right)$, Canad. J. Math., 25 (1973), 92-95.

Received July 12, 1986. The author was supported in part by Grand-in-Aid for Scientific Research, Ministry of Education.

KANAGAWA UNIVERSITY

YOKOHAMA 221, JAPAN 


\section{EDITORS}

\author{
V. S. VARADARAJAN \\ (Managing Editor) \\ University of California \\ Los Angeles, CA 90024 \\ HeRbert Clemens \\ University of Utah \\ Salt Lake City, UT 84112 \\ R. FINN \\ Stanford University \\ Stanford, CA 94305
}

\author{
HERMANN FLASCHKA \\ University of Arizona \\ Tucson, AZ 85721 \\ RAMESh A. GANGOLLI \\ University of Washington \\ Seattle, WA 98195 \\ VAUGHAN F. R. JONES \\ University of California \\ Berkeley, CA 94720
}

\author{
ROBION KIRBY \\ University of California \\ Berkeley, CA 94720 \\ C. C. MOORE \\ University of California \\ Berkeley, CA 94720 \\ HAROLD STARK \\ University of California, San Diego \\ La Jolla, CA 92093
}

\section{ASSOCIATE EDITORS}
R. ARENS
E. F. BECKENBACH
B. H. NEUMANN
F. WOLF
K. YOSHIDA
(1906-1982)

\section{SUPPORTING INSTITUTIONS}

UNIVERSITY OF ARIZONA
UNIVERSITY OF BRITISH COLUMBIA
CALIFORNIA INSTITUTE OF TECHNOLOGY
UNIVERSITY OF CALIFORNIA
MONTANA STATE UNIVERSITY
UNIVERSITY OF NEVADA, RENO
NEW MEXICO STATE UNIVERSITY
OREGON STATE UNIVERSITY

\author{
UNIVERSITY OF OREGON \\ UNIVERSITY OF SOUTHERN CALIFORNIA \\ STANFORD UNIVERSITY \\ UNIVERSITY OF HAWAII \\ UNIVERSITY OF TOKYO \\ UNIVERSITY OF UTAH \\ WASHINGTON STATE UNIVERSITY \\ UNIVERSITY OF WASHINGTON
}

The Supporting Institutions listed above contribute to the cost of publication of this Journal, but they are not owners or publishers and have no responsibility for its content or policies.

Mathematical papers intended for publication in the Pacific Journal of Mathematics should be in typed form or offset-reproduced (not dittoed), double spaced with large margins. Please do not use built up fractions in the text of the manuscript. However, you may use them in the displayed equations. Underline Greek letters in red, German in green, and script in blue. The first paragraph must be capable of being used separately as a synopsis of the entire paper. In particular it should contain no bibliographic references. Please propose a heading for the odd numbered pages of less than 35 characters. Manuscripts, in triplicate, may be sent to any one of the editors. Please classify according to the scheme of Math. Reviews, Index to Vol. 39. Supply name and address of author to whom proofs should be sent. All other communications should be addressed to the managing editor, or Elaine Barth, University of California, Los Angeles, California 90024.

There are page-charges associated with articles appearing in the Pacific Journal of Mathematics. These charges are expected to be paid by the author's University, Government Agency or Company. If the author or authors do not have access to such Institutional support these charges are waived. Single authors will receive 50 free reprints; joint authors will receive a total of 100 free reprints. Additional copies may be obtained at cost in multiples of 50 .

The Pacific Journal of Mathematics is issued monthly as of January 1966. Regular subscription rate: $\$ 190.00$ a year (5 Vols., 10 issues). Special rate: $\$ 95.00$ a year to individual members of supporting institutions.

Subscriptions, orders for numbers issued in the last three calendar years, and changes of address should be sent to Pacific Journal of Mathematics, P.O. Box 969, Carmel Valley, CA 93924, U.S.A. Old back numbers obtainable from Kraus Periodicals Co., Route 100, Millwood, NY 10546.

The Pacific Journal of Mathematics at P.O. Box 969, Carmel Valley, CA 93924 (ISSN 0030-8730) publishes 5 volumes per year. Application to mail at Second-class postage rates is pending at Carmel Valley, California, and additional mailing offices. Postmaster: send address changes to Pacific Journal of Mathematics, P.O. Box 969, Carmel Valley, CA 93924.

PUBLISHED BY PACIFIC JOURNAL OF MATHEMATICS, A NON-PROFIT CORPORATION Copyright (c) 1987 by Pacific Journal of Mathematics 


\section{Pacific Journal of Mathematics}

\section{Vol. 130, No. $2 \quad$ October, 1987}

Bernhard Banaschewski, J. L. Frith and C. R. A. Gilmour, On the congruence lattice of a frame ............................ 209

Paul S. Bourdon, Density of the polynomials in Bergman spaces ........2215

Lawrence Jay Corwin, Approximation of prime elements in division

algebras over local fields and unitary representations of the multiplicative group

Stephen R. Doty and John Brendan Sullivan, On the geometry of extensions of irreducible modules for simple algebraic groups

Karl Heinz Dovermann and Reinhard Schultz, Surgery of involutions

with middle-dimensional fixed point set ....................2 275

Ian Graham, Intrinsic measures and holomorphic retracts ............ 299

John Robert Greene, Lagrange inversion over finite fields . . . . . . . . . . . 313

Kristina Dale Hansen, Restriction to $\mathrm{GL}_{2}(\mathrm{O})$ of supercuspidal

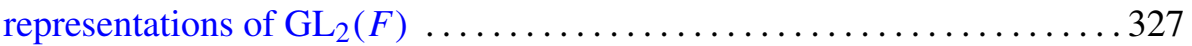

Kei Ji Izuchi, Unitary equivalence of invariant subspaces in the polydisk ....351

A. Papadopoulos and R. C. Penner, A characterization of pseudo-Anosov

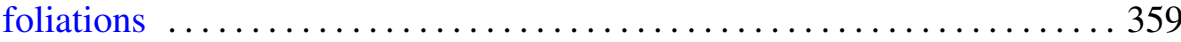

Erik A. van Doorn, The indeterminate rate problem for birth-death

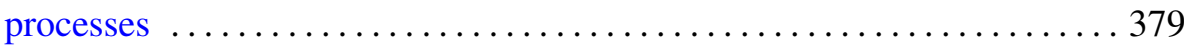

Ralph Jay De Laubenfels, Correction to: "Well-behaved derivations on

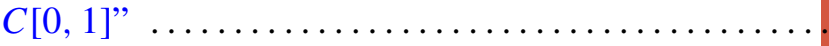

Robert P. Kaufman, Correction to: "Plane curves and removable sets" . . . . 396

Richard Scott Pierce and Charles Irvin Vinsonhaler, Correction to:

"Realizing central division algebras" 